\title{
The Artistic Style and Application Research of Macheng Folk Paper-cut
}

\author{
Zehui Gong \\ Academy of Fine Arts \\ Huanggang Normal College \\ Huanggang, China
}

\begin{abstract}
Macheng Paper-cut art is the protection project of Macheng's local intangible cultural heritage, with deep humanistic connotations and abundant cultural value. This paper took the artistic style of Macheng folk Paper-cut as its study point; according to the style analysis on Macheng folk Paper-cut art works, this paper summarized the artistic characteristics of Macheng folk Paper-cut, and explored the prospect of Macheng folk Paper-cut's development and application by aspects like image expression and style explanation, etc.; it also combined with the market to positively find the possibility of promoting Paper-cut art business. The study of the paper is beneficial for not only the overall cognition of Macheng folk Paper-cut art, but also the protection, inheritance and promotion of the intangible cultural heritage project.
\end{abstract}

Keywords-Macheng folk Paper-cut; artistic style; application research

\section{INTRODUCTION}

At the beginning of 21 st century, with the development of the protection cause of the world intangible cultural heritage in China, people started to realize the value of culture root's existence and extension. It was in the rapidly changing and developing reality under nowadays' background of globalization that Chinese folk fine arts stepped on the historical stage. However, in recent years, with the rapid development of the society, the fast-food age has changed people's life, and then directly impacted folk fine arts. Folk fine arts are stories of people and the land, people and the nature, as well as life. They focus on traditional folk customs and folk arts, carry forward Chinese culture, and find the cultural root maintained by countless laboring people of Chinese nation with human emotions; it is also a contemporary task urgently needing to be solved. Paper-cut, as one of the most commonly used, the most primitive and the most diversified active cultures, is an important "parent-body art", playing an irreplaceable role in the life of traditional folk customs. Macheng folk fine arts are of a great number. Paper-cut, as one kind of Macheng folk fine arts, has not been as well-known by people as local folk fine arts. The author investigated and learned about the

Project Number: 2015021003 Project Type: Youth Scientific Research Fund. Project Title: The Artistic Style and Application Research of Macheng Folk Paper-cut. Notes: this paper is written by the author and is included in the youth scientific research project of Huanggang Normal College in 2015. existing condition of Macheng folk Paper-cut by visiting and interviewing; the author also collected relevant materials, and found the diversity of Macheng folk Paper-cut artistic style; according to the field research, the author had several new thoughts about Macheng folk Paper-cut and some new ideas about the development of the future of Macheng folk Paper-cut, which made the author determined to write the paper.

\section{The ARTISTIC STYLE OF MACHENG FOLK PAPER-CUT}

Paper-cut in the folk arts and crafts, in accordance with tool materials, is classified as a separate style. It uses scissors to cut out various shapes of paper, and takes the technique of alternating with abstraction and concreteness to describe internal lines and patterns, and compares the abstraction and the concreteness to embody the image, and also reserves lines and planes in different cutting techniques to express the image characteristics. Paper-cut is the most common, the most primitive and the most diversified active culture used in traditional Chinese folk life.

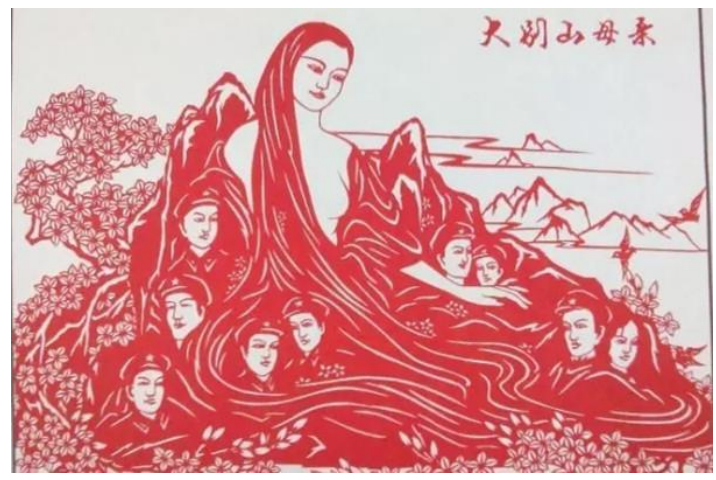

Fig. 1. Mother of Dabie Mountain.

Macheng, located at the southern foot of the middle part of Dabie Mountain, is one of the birthplaces of Huangma Uprising. The full-bodied red blood flows in Macheng, which manifests the strong red spirit. Moreover, Macheng is of marvelous mountains and graceful water, as well as colorful and beautiful flowers. It says, "on the days of April in the world, the azalea flowers in Macheng is highly worth watching". Therefore, the folk fine art growing out of the soil of the old revolutionary base area is unadorned and touching. 
Macheng folk Paper-cut truly and deeply expresses its motherland's unique temperament by its special techniques. "Fig. 1" Mother of Dabie Mountain uses personification and the knife-cutting technique to describe Macheng at the foot of Dabie Mountain as a gentle mother. Surrounding the body of the mother, there are a group of soldier figures that protect Dabie Mountain, the mother and the country. Similarly, in "Fig. 2" Sending My Darling to the Army lively depicts the theme of the Red Army again. Looking from the whole image, Sending My Darling to the Army shows an intimate couple is unwilling to leave each other. From the details of the image, their promises and waiting for each other can be clearly felt from their eye contact. The most beautiful love in the world is described to be so exciting and touching only by a pair of scissors and a piece of red paper.

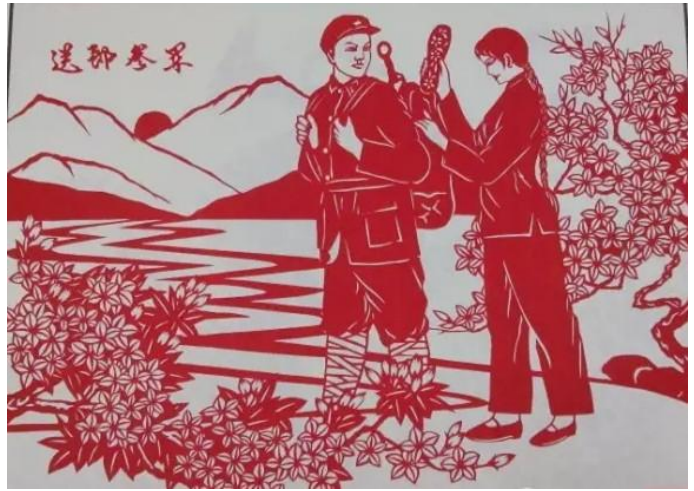

Fig. 2. Sending My Darling to the Army.

According to the comprehensive analysis on Macheng folk Paper-cut artistic style, the author found that the Macheng folk Paper-cut expressing the theme of the Red Army really occupied a certain part of Macheng folk Papercut. Each place has its own way to raise its people, and the place and the people cultivate their own culture; the culture gradually becomes as tradition, and now the tradition is feeding and restraining generations of descendants in return. Apart from the red and manly beauty, Macheng also has the beauty rendered by mountains and waters. The mentionable thing is that the image styles of Macheng folk Paper-cut in recent years are mostly describing the sceneries of local mountains and waters, such as Macheng's famous "Three Platforms and Eight Sceneries", "Xinghua Village", "Azalea flowers on Guifeng Mountain", etc. As the national 5A scenery spot, Guifeng Mountain is not only famous for its azalea flower sea, but also for its high and precipitous mountains, especially the turtle-head-shaped peak rising straight from continuously rolling mountains. The peak's vertical height reaches more than 300 meters, surrounded by white clouds all day long; climbing on the top of the peak is like entering into a fairyland. Macheng Guifeng Mountain scenery spot shows its special beauty to visitors. "Fig. 3" Azalea Flower Sea, as an excellent work of scenery theme among Macheng folk Paper-cut works, shows Guifeng Mountain's beauty by the artist's hands. By watching the work from the main body of Guifeng Mountain, the azalea flower sea, and the figures in that natural scenery, it can make audience feel really in the scenery themselves. By facing the work, the fragrance of flowers can be smelled. The expressions in the work, especially the expression of the flower sea, not only require manual techniques, but also test the Paper-cut artists' carefulness and enthusiasm for Papercut art.

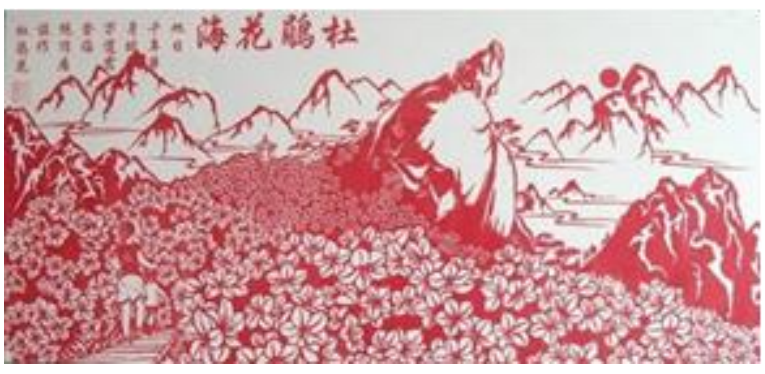

Fig. 3. Azalea Flower Sea.

All those Paper-cut works are from the famous artist of Macheng folk Paper-cut Liu Jinrong. Liu Jinrong's Paper-cut art is also gradually inherited from the old generation since she was young. She takes paper as medium, with scissors flexibly running in her hands and scraps of paper falling down on the ground. Whether Paper-cuts are about flowers, birds, fishes and insects, auspicious patterns, water and mountain landscapes, or historical stories, folklores and historical sites, she can always make them delicate and vivid, plump and fresh in her hands. After visited for a long time, Master Liu said to the author, "My Paper-cut works used to be mainly based on flowers, plants and animals. This time's creation mainly pointed out Macheng's sceneries, so I cut out scenery images. During the creation, I mainly highlighted the combination of waters and mountains, as well as the depth of waters and mountains". The Paper-cut studio of Master Liu is located in Sanhekou Town, Macheng City. The folk Papercut with characteristics of Sanhekou Town is of around 1000 years of history; it takes paintings as patterns, with wideranging themes, concise image composition, and round and smooth lines, delicate and beautiful, which gives people a sense of massiveness and completion. There are hundreds of Paper-cut experts, but the most representative one among young experts is Master Liu. Her works are mainly about animals, waters and mountains, flowers and plants. Her cutting technique is fine and smooth, and her works look vivid and lively. Chairman of the Women's Association of Macheng Chi Liping sighed with emotion while her watching at Sanhe Paper-cuts, "The Paper-cut works of Liu Jinrong are pretty good. No matter those are Paper-cuts showing Macheng's regional features such as Azalea Flower Sea and Shepherd Boy Remotely Pointing at Xinghua Village, or Paper-cuts of people's life such as Village Bonfire and Keep Watching, they all look so vivid and lively."

Paper-cut is an art of hollowing out, conveying a seethrough sense and a unique artistic appeal. Folk Paper-cut is not restricted by the objective, expressing natural sceneries' full view in the flat two-dimensional space by the "splattering" observation method of multi-angle of view and multi-direction. Folk Paper-cut, with bright and enthusiastic colors and simple image planes, is not limited by the proper colors of objects and sceneries. Paper -cut art is widely spread in China, because the art symbolizes the beautiful and 
nice things, but also produces many art works of great ornamental value and decorative style. Those works show elegance in simplicity and freedom in massiveness, and are of slender and meaningful style, with the alternating of lines and planes, the jagging of abstraction and concreteness, the fine density, and the plump image composition. All those give audience a sense of simplicity, purity, healthiness, and vividness, as well as a strong local color and a strong local flavor.

In addition of themes summarized above, Macheng folk Paper-cut also has quite a number of works with traditional themes of dragon and phoenix totems. The performance of those themes is derived from the belief and worship of Chinese laboring people to their traditional culture. Especially in the county-level small city as Macheng, the rootedness of people's traditional thinking has directly affected all aspects of life, such as folk Paper-cut with traditional techniques indicating beautiful and good things. The modeling of "Fig. 4" Scrambling for the Bead Between Dragon and Phoenix is vivid, with fluent lines, lifelike artistic conception and traditional art of composition. In modern life, the dragon and phoenix decoration is very commonly used, especially in Paper-cut pattern modeling where dragon and phoenix decoration is more widely used. Its iconic modeling represents completeness, happiness, auspiciousness, wealth; through traditional graphic patterns such as "dragon and phoenix flying", "all birds flying to phoenix" and "red phoenix in morning sun" etc., it meets people's aesthetic needs and spiritual gratification needs. Due to its strong vitality, the graphic pattern of dragon and phoenix is deeply rooted in people's life, throughout a wide range of fields of production and operation. It is a practical material used in modern decorative design, pottery design, costume design, marriage celebrations and other activities.

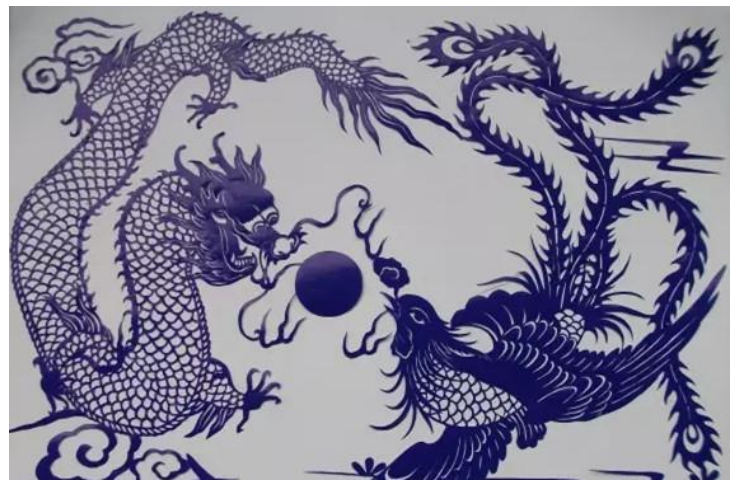

Fig. 4. Scrambling for the Bead Between Dragon and Phoenix.

Macheng folk Paper-cut artistic style is changing from traditional to modern. With the inheritance of its tradition, Macheng folk Paper-cut actively walks on the road of innovation - the innovation of Paper-cut techniques and themes. Macheng folk Paper-cut needs to not only highlight the red spirit of Macheng, but also get into ordinary people's life; it not only needs to be inherited but also needs to be carried forward. The infusion of modern themes is a reflection of actively looking for the road of innovation. "Fig. 5" Harmony is a microcosm of thousands of families in
China. In the image, the granddaughter is doing a back massage for the grandmother, and the daughter-in-law is clearing up the fallen hair of the elder. It shows a happy family of old people and young people, with a kind of peace and happiness vividly on the image. Harmony is a luxury for the stressful and impetuous age. The harmony between human and the nature and the harmony between people, from the harmony of one family to the harmony of everyone, are worth everyone's deep thinking, which is also a lifetime-long pursuit of everyone. This folk Paper-cut work uses itself to preach the concept of harmony. As the great theorist of China said, the purpose of painting is to see the ups and downs, rise and decline in thousands of years by observing the painting. The same is true for Paper-cut.

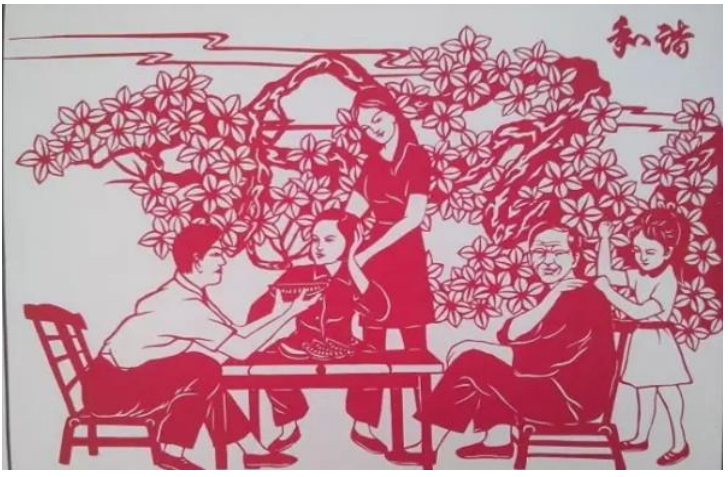

Fig. 5. Harmony.

The artistic characteristics are shown by the regional cultural characteristics of Paper-cut, and the regionalism constitutes the diversity of the traditional culture of Paper-cut art. The main body of the inheritance of Chinese folk Papercut tradition is millions of laboring women groups in Chinese rural areas, and the Paper-cut tradition with deep deposits is inherited in the passing on by words of generations of rural women. Villages of different ethnic groups in different regions have their own talented inheritors of Paper-cut tradition. These inheritors have outstanding Paper-cut skills, and the more important thing is their Papercut cultural memory and cultural creation, representing their regions' cultural temperament and artistic level.

Macheng folk Paper-cut, during the process of its inheritance and protection, highlights the geographical characteristics and cultural value of folk Paper-cut arts. First of all, as an intangible cultural heritage, folk Paper-cut art is a result of the collective wisdom of different generations, and a part of important arts and cultural value in China's traditional culture, which has been explained by Macheng folk Paper-cut artistic style.

\section{THE PROMOTION AND INHERITANCE OF MACHENG FOLK PAPER-CUT}

Because of forgetting, remembering is needed. As a folk art originated in laboring people, Macheng folk Paper-cut art needs to be known, inherited and protected.

The abundant graphic appearances of traditional Papercut art and the deep mass base of folk art all provide 
conditions for modernization development, and also for the popularized and commercialized transformation of Paper-cut. It can be certain that in the contemporary social environment, people have more cultural consumption needs and choices. Under the insistence on the principle of integrated preservation, the protection and development of intangible cultural heritage projects should actively seek for survival and development spaces under the background of the new era, and scale up by the double-way development of using, promotion, industry and publicity, as well as opportunities such as the mass market, tourism, education etc., to achieve the existence and development of intangible cultural heritage and achieve the virtuous circle of the existence and development of intangible cultural heritages.

Firstly, combine Macheng folk Paper-cut with local sceneries, which shows the combination of folk Paper-cut art and local tourism economic development. with the constant rising of the economic development of Macheng tourism, as well as the publicity and momentum-building of special scenery spots, the number of Macheng tourism visitors has reached to more than 200 thousand in fixed quarters. If take Macheng tourism as a kind of tourism goods into the market, the aesthetic, historical and cultural value, scientific investigation value and the economic value of its tourism value will be reflected in the Paper-cut. Macheng folk Papercut, developed as a special tourism product, has considerable economic benefits. Effectively promoting Macheng Papercut as a tourist good, a tourist attraction, and a tourist souvenir, expanding its popularity and cognition degree among people, meeting the consumption desires of tourists, striving to open up the market and gradually walking to industrialization, marketization and Popularization can pour a new vitality into Macheng cultural industries and tourism industry. On the basis of the high attention of the Party Central Committee on the development of science and technology as well as being diligent and thrifty, Macheng folk Paper-cut keeps up with the pulse of the time by promoting "frugal tourism" and "humanistic tourism".

Secondly, combine Macheng folk Paper-cut with local economic development, which has a realistic and feasible meaning. Macheng folk Paper-cut art shows Macheng cultural deposits, and expresses "the dream of Macheng", "the red dream" and "the dream of tourism", which can improve people's aesthetic conception and spiritual pursuit.

Thirdly, Macheng folk Paper-cut art, by the way of rolling snowballs, has gathered a batch of outstanding young Paper-cut artists, such as the Paper-cut successor of Sanhekou Town in Macheng Liu Jinrong. She set up her own studio -- Liu Jinrong Paper-cut Studio. It is worth noting that, on the one hand, traditional Macheng Paper-cut has outstanding and innovative appearance feature on its forms and crafts, compared to before. this feature is related to the thinking of folk artists in the process of technique inheritance; on the other hand, the feature of Macheng Paper-cut forms consciously performs local characteristics, with a value to manifest the local folk culture. However, according to the current status of Macheng Paper-cut, the way of Paper-cut art promotion is narrow, and it is easy to duplicate. In a fiercely competitive market environment, if there is no strict market regulation or lack of industry self-discipline, the situation of plagiarism is quite difficult to avoid. This kind of situation will definitely affect the production of excellent Paper-cut works and the development of excellent artists. How to strengthen the copyright awareness of Paper-cut artists, how to protect intellectual property rights by legal means, and how to promote the benign competition of artistic creation and market operation are all worth our thinking.

At last, the studios of Macheng Paper-cut engaged in the creation and production belong to small micro enterprises. Small and micro enterprises are the new force of national economic development, playing a significantly important role in aspects, such as the stable growth, job enlargement, promotion of innovation, prosperity of the market and meeting the needs of the people, etc.; but, at the same time, they need more policy support and guidance, and also need more scholars and cultural workers to get involved in, deeply explore the cultural value of Macheng Paper-cut, to give suggestions and advice on the development of the industry. In recent years, the Party Committee of Sanhekou Town positively response to the government's call to protect national intangible cultural heritages, vigorously protect and promote Sanhe Paper-cut. Liu Jinrong's Paper-cut art has become more and more delicate, and its influence has also grown bigger, so the ancient culture and art has been inherited by the peasant woman. However, Sanhekou Town is located in the northeast of Macheng, and is at the junction of Hubei, Henan and Anhui Provinces. Moreover, this place is remote, surrounded by groups of mountains, with bad traffic, so foreign cultures are difficult to get into the town and the local culture is more difficult to spread out. The problem always concerned by the Party Committee of Sanhekou Town is how to make the ancient art be more widely spread and produce more benefits in the process of its inheritance, and how to let the small Paper-cut run out of the small village and let rural women find a new world to start businesses. Today, Sanhekou Town has contacted with Macheng Women's Association to discuss about this issue. They will actively help Liu Jinrong to expand the sales channels of Paper-cut by exploring the e-commerce training mode of network and practice, actively explore the sales channels of Sanhe Paper-cut by holding diversified activities such as entrepreneurial education, training camps and innovative products exhibitions, etc., as well as by carrying out the "Internet plus" women entrepreneurship innovation activities, hoping that Liu Jinrong Paper-cut demonstration site can be an opportunity to promote and drive the majority of women compatriots to start up business or get a job, as well as to lead women start up business or get a job in the new pattern of the new status of the new industry.

In addition, Paper-cut, as a traditional folk art, has its own unique aesthetic education significance on how to continue to carry forward aesthetic education and cultural heritage, and bring Paper-cut into classes under the impact of various flashy cultures. Paper-cut teaching brings students a new understanding of Chinese folk traditional crafts; Papercut activities, as a form of artistic education, promote students to design and operate by their own hands, which not only teach students how to observe life, but also make their 
inheritance of folk art from a young age. Through the visits to several local Macheng Primary and middle schools, the author found that Paper-cut class was now incorporated into the textbooks of fine arts class teaching and had walked into classrooms; however, the class time of Paper-cut was generally arranged in about two sections, and most of classes were mainly taught by only referring to textbooks. In general, compared to before, more attention has been paid to the designing of the textbooks of physical education, music and art classes. The author thinks if use local resources and invite local Paper-cut artists Paper-cut artists into classrooms, there will be more fun, and it will also stimulate children's learning motivation and play an important role in the inheritance and protection of Paper-cut art.

\section{CONCLUSION}

In conclusion, Macheng folk Paper-cut art has its own unique regional style, and is also affected by the limitation of many aspects at the same time. Therefore, the folk art that is supposed to give out light didn't receive much attention from people. The author thought Macheng folk Paper-cut art not only needed not people's efforts, but also required the excavation of, the care for and the publicity of the local culture from governments at all levels, especially the local government. The carrying forward of folk fine arts still has a long way to go.

\section{REFERENCES}

[1] Zhang Zichen.1990. "Folklore and Folk Fine Arts" [M]. Changsha: Hunan Fine Arts Publishing House.

[2] Chen Jing.1992. "Research on Chinese Folk Paper-cut Art" [C]. Beijing Arts and Crafts Publishing House.

[3] Jiang Jian.1993. "The Polyisomerism of Folk Paper-cut" [J]. Art Research.

[4] Zuo Hanzhong.1995. "Horizontal and Vertical Perspective of Chinese Folk Paper-cut" [J] Root Exploration.

[5] Jin Zhilin.2003. "Discussion on Chinese Folk Art" [J]. Art Research.

[6] Liu Qiang.2010. "First Exploration of Folk Paper-cut and Folk Culture" [J]. Mass Literary Magazine. 